\title{
Turismo ferroviário e de base comunitária: algumas conexões para o planejamento e a gestão
}

Tourist Railway and Tourism Community-Based: some connections for planning and management

Turismo Ferroviario y Turismo de Base Comunitaria: algunas conexiones para su planificación y gestión

http://dx.doi.org/10.18472/cvt.18n1.2018.1478

Carla Conceição Lana Fraga <carlota.fraga@gmail.com >

Universidade Federal do Estado do Rio de Janeiro (Unirio), Rio de Janeiro, RJ, Brasil

Vera Lúcia Bogéa Borges 〈vera.borges@unirio.br >

Universidade Federal do Estado do Rio de Janeiro (Unirio), Rio de Janeiro, RJ, Brasil

CRONOLOGIA DO PROCESSO EDITORIAL

Recebimento do artigo: 29-ago-2017

Aceite: 15 -jan-2018

FORMATO PARA CITAÇÃO DESTE ARTIGO

FRAGA, C. C. L.; BORGES, V. L. B. Turismo Ferroviário e de Base Comunitária: algumas conexões para o planejamento e a gestão. Caderno Virtual de Turismo. Dossiê Temático: II Seminário Nacional de Turismo e Cultura da Fundação Casa de Rui Barbosa. Rio de Janeiro, v. 18, n. 1, p. 28 39, abr. 2018.

REALIZAÇÃO

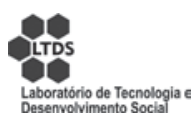

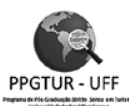

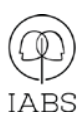

APOIO INSTITUCIONAL

COPPE

UFR]
EDIÇÃO

PATROCÍNIO

EDITORA

IF日s 


\section{RESUMO}

O turismo ferroviário no Brasil é promissor, o que enseja reflexões sobre sua relação com a "base comunitária" na perspectiva do envolvimento de atores e organizações. Foram selecionados dez casos de trens turísticos e culturais para análise neste estudo exploratório realizado por meio da consulta a websites. Esses casos são oriundos de vários estados brasileiros e operados por diferentes tecnologias ferroviárias (a vapor e eletrificado). Com base na literatura sobre ferrovia e turismo, e turismo de base comunitária, considerou-se como eixos para a análise do Turismo Ferroviário de Base Comunitária (TFBC): (1) localização geográfica dos trechos ferroviários; (2) história como uma representação do passado; (3) memória como um elo vivo entre o passado e o presente. As principais contribuições alcançadas foram: (1) problematização inicial a respeito do TFBC; (2) análise de parte do cenário brasileiro.

Palavras-chave: Turismo e Ferrovia. Turismo Base Comunitária. Planejamento e Gestão.

\section{ABSTRACT}

Rail tourism in Brazil is promising, enabling reflections about his relationship to the "community-based" in a perspective of the involvement of actors and organizations. In this exploratory study we selected ten cases of cultural and tourist trains for analysis based on websites research. These cases are from several states in Brazil and are operated by different railway technologies (steam, electrified). Based on the literature on railway and tourism, and community-based tourism, it was considered as axes for the analysis of Community - Based Rail Tourism (CBRT): (1) geographic location of the rail segments; (2) history as a representation of the past; (3) memory as a living link between the past and the present. The main contributions were achieved: (1) initial questioning about the CBRT; (2) analysis of some parts of the Brazilian scenario.

Keywords: Tourism and Railway. Community-Based Tourism. Planning and Management

\section{RESUMEN}

El turismo ferroviario en Brasil es promisor, lo da lugar a reflexiones acerca de sus vínculos con una "base comunitaria" en la perspectiva de involucrar actores e organizaciones. Para este trabajo, de abordaje exploratorio, han sido seleccionados diez casos de trenes turísticos y culturales para un análisis a través de websites. Estos casos son oriundos de varios estados brasileños y operados por distintas tecnologías ferroviarias (a vapor, electrificado). A partir de la literatura acerca de ferrocarriles y turismo, y turismo de base comunitaria, han sido considerados algunos ejes analíticos para el estudio del Turismo Ferroviario de Base Comunitaria: 1) ubicación geográfica de los tramos 2) historia como una representación del pasado 3) memoria como una correspondencia viva entre pasado y presente. Los principales aportes de este trabajo son 1) una problematización inicial acerca del TFBC; 2) un análisis parcial del contexto brasileño en este tema.

Palavras clave: Turismo. Ferrocarriles. Turismo de Base Comunitaria. Planificación y gestión. 


\section{INTRODUÇÃO}

O turismo de base comunitária [TBC], enraizado num processo situado de desenvolvimento, é uma modalidade do turismo sustentável cujo foco principal é o bem-estar e a geração de benefícios para a comunidade receptora (BURSZTYN; BARTHOLO; DELAMARO, 2009, p. 86).

Como o turismo de base comunitária articula-se com o planejamento, gestão e desenvolvimento do turismo ferroviário no Brasil? No contexto de expansão da oferta ferroviária turística brasileira, a cartilha que orienta a proposição de novos projetos de trens turísticos e culturais no País indica a necessidade de uma série de documentos e estudos, entre eles: “(...) benefícios econômico-financeiros decorrentes do empreendimento [trens turísticos e culturais] contendo a repercussão econômica e social nas comunidades e na região abrangida, bem como no desenvolvimento turístico e cultural" (BRASIL, 2010, p. 31), o que inspira a problematizar a necessidade da construção de um novo referencial teórico sobre a relação entre turismo e a ferrovia no Brasil, isto é, sobre as possibilidades e os desafios para o Turismo Ferroviário de Base Comunitária (TFBC).

A primeira ferrovia construída no Brasil data de 1854, ou seja, são mais de 160 anos de história da ferrovia e várias etapas que incluem avanços e retrocessos na extensão da malha ferroviária brasileira. Atualmente são aproximadamente 29 mil quilômetros de ferrovia, e a maior parte dessa malha é concessionada à iniciativa privada, grande interessada no transporte de carga (FRAGA, 2011; FRAGA, 2013). De acordo com o Ministério do Turismo, existem 33 trens e bondes para fins turísticos no Brasil, entre os que estão em operação, os desativados e os que serão inaugurados (BRASIL, s.d.). A Associação Brasileira das Operadoras de Trens Turísticos e Culturais (ABOTTC) e o Serviço Brasileiro de Apoio às Micro e Pequenas Empresas (Sebrae), considerando 21 linhas de trens turísticos e culturais no País, apontaram para a meta de atender em dois anos:

\footnotetext{
[...] por meio da melhoria da operação desses trens, cerca de 600 empreendimentos entre lojas, pousadas e hotéis, restaurantes, artesanato local, serviços de táxis e guias de turismo situados nas imediações das linhas, além dos próprios funcionários das concessionárias dos trens (ABOTTC; SEBRAE, 2015, p. 1)
}

A citação instiga a refletir sobre as várias comunidades receptoras que podem estar envolvidas direta e indiretamente nos roteiros ferroviários turísticos brasileiros e os seus respectivos papéis para o desenvolvimento dessa modalidade de turismo no País. Como mencionado, o TBC é enraizado em um processo situado de desenvolvimento, assim, surge a seguinte questão inicial com vistas à construção de um referencial teórico sobre o TFBC: Qual é a relação entre o turismo ferroviário e o turismo de base comunitária?

Para responder, mesmo que inicialmente e de maneira parcial, a essa questão foi realizado um levantamento bibliográfico no qual se identificou a ampliação do diálogo entre ferrovia e turismo, incluindo as questões relativas à "base comunitária". A partir desse levantamento bibliográfico notou-se a relevância de aspectos geográficos, históricos e relativos à memória, como eixos para a construção de critérios para a análise de conexões entre o turismo ferroviário e o turismo de base comunitária. A partir daí, foram selecionados dez trens turísticos e culturais no Brasil para a análise.

As próximas três seções estão organizadas a fim de dar fluxo a essa discussão preliminar sobre a temática, desde o embasamento teórico até a construção de critérios, e posterior análise e discussão sobre os resultados encontrados. 


\title{
TURISMO FERROVIÁRIO DE BASE COMUNITÁRIA (TFBC)
}

As reflexões produzidas sobre o Turismo de Base Comunitária (TBC) marcam importante conquista para o turismo a partir da perspectiva do binômio da inclusão social e da discussão sobre participação social das populações locais como protagonistas do processo turístico. Nessa direção, Irving (2009, p. 111) afirma que:

\begin{abstract}
o sentido de comunitário transcende a perspectiva clássica das "comunidades de baixa renda" ou "comunidades tradicionais" para alcançar o sentido de comum, e coletivo. O turismo de base comunitária, portanto, tende a ser aquele tipo de turismo que, em tese, favorece a coesão e o laço social e o sentido de coletivo de vida em sociedade, e que por esta via, promove a qualidade de vida, o sentido de inclusão, a valorização da cultura local e o sentimento de pertencimento. Este tipo de turismo representa, portanto, a interpretação "local" do turismo, frente às projeções de demandas e de cenários do grupo social do destino, tendo como pano de fundo a dinâmica do mundo globalizado, mas não as imposições da globalização. (IRVING, 2009, p. 111)
\end{abstract}

A globalização está na ordem do dia, uma palavra da moda que se transforma rapidamente em um lema, um encantamento mágico, uma senha capaz de abrir as portas dos mistérios sejam estes do presente ou, ainda, do futuro. De forma geral, porém, globalização parece ser compreendida como destino irremediável do mundo, um processo irreversível como se todos nós estivéssemos sendo globalizados e isso significasse basicamente o mesmo para todos. Frequentemente, as palavras da moda tendem a um mesmo destino, quanto mais experiências pretendem explicar, mais opacas se tornam. Portanto, no fenômeno da globalização, há mais coisas do que se pode apreender a olho nu. Nesse sentido, Bauman (1999) alerta-nos para que o foco das discussões esteja nas raízes e consequências sociais do processo globalizador e que assim possa ser dissipada a névoa que cerca esse termo. Comumente, os processos globalizadores não têm a unidade de efeitos. Os usos do tempo e do espaço são acentuadamente diferenciados e diferenciadores. O que para alguns parece globalização, para outros significa localização, o que para alguns é sinalização de liberdade, para muitos outros é um destino indesejado e cruel.

Assim, quando trazemos essa discussão para o turismo, e mais especificamente para o turismo de base comunitária, alguns elementos-chave devem ser observados. Em busca de indicadores de desempenho de turismo de base comunitária na perspectiva da sustentabilidade, Fabrino et al. (2012) estabeleceram seis elementos-chave do TBC que estão descritos na Tabela 1:

Tabela 1 - Indicadores de desempenho TBC na perspectiva da sustentabilidade

\begin{tabular}{|l|l|}
\hline Dominialidade & $\begin{array}{l}\text { "refere-se ao grau de domínio da comunidade sobre os aspectos de organização, } \\
\text { controle, propriedade e gestão da atividade turística". }\end{array}$ \\
\hline Interculturalidade & $\begin{array}{l}\text { "relaciona-se com o intercâmbio cultural e a troca de referências e experiências } \\
\text { estabelecidas entre os turistas e a comunidade local”. }\end{array}$ \\
\hline $\begin{array}{l}\text { Organização } \\
\text { Social }\end{array}$ & $\begin{array}{l}\text { "almeja identificar o modelo e processo de gestão comunitária consolidada em torno } \\
\text { do TBC, além de sua interação com o ambiente externo, por meio da participação em } \\
\text { redes, comitês, conselhos, etc.". }\end{array}$ \\
\hline $\begin{array}{l}\text { Repartição de } \\
\text { benefícios }\end{array}$ & $\begin{array}{l}\text { "refere-se à existência de mecanismos de distribuição de renda e de investimentos, } \\
\text { de modo includente, em projetos beneficiando a comunidade resultante da atividade } \\
\text { turística". }\end{array}$ \\
\hline $\begin{array}{l}\text { Integração } \\
\text { econômica }\end{array}$ & $\begin{array}{l}\text { "evidencia a integração do turismo com as atividades econômicas tradicionais, } \\
\text { identificando os novos arranjos produtivos locais surgidos a partir do seu advento". }\end{array}$ \\
\hline $\begin{array}{l}\text { Gestão dos bens } \\
\text { comuns }\end{array}$ & $\begin{array}{l}\text { "relaciona-se com as instituições internas e articulações externas promovidas pelas } \\
\text { iniciativas comunitárias na gestão e salvaguarda dos bens comuns. Ressalta-se que } \\
\text { as experiências de TBC são reconhecidas pela alta capacidade de manejo e defesa } \\
\text { dos recursos naturais". }\end{array}$ \\
\hline
\end{tabular}

Fonte: Fabrino et al. (2012, p. 557) 
Ainda que o foco deste estudo seja os trens turísticos e culturais, é válido contextualizar alguns exemplos das possibilidades de ampliação da discussão sobre turismo ferroviário e suas interfaces e derivações (Rail Trail, Turismo de Draisines, Rail Biking, etc.), pois estas também poderão fazer parte da discussão sobre a "base comunitária". É evidente que o turismo ferroviário está além da simples relação entre turismo e ferrovia, pois exige organização, planejamento e políticas públicas para a sua estruturação e sustentação. A existência do fenômeno turístico em uma dada área geográfica que apresenta ferrovia não necessariamente originará o desenvolvimento do turismo ferroviário (FRAGA et al., 2015).

Os transportes ferroviários enquanto uma tecnologia composta por um conjunto de elementos, como via, veículo, força motriz e terminal (PALHARES, 2002), com características próprias, influenciam e são influenciados por um dado sistema cultural fluido. Assim, na literatura, fica evidenciada a importância de uma discussão sobre ferrovia e turismo ampliada, nota-se:

(a) a relevância da paisagem ferroviária (FRAGA et al., 2015), o que inclui discussões sobre imagem e o imaginário;

(b) o papel do patrimônio ferroviário (material e imaterial) imbricado nos desdobramentos da cultura ferroviária (ALLIS, 2002), traduzido por um conjunto de signos e significados que vão além das vias segregadas (trilhos) em si (FRAGA; FROSSARD, 2014; FRAGA; SANTOS; RIBEIRO, 2014);

(c) a história e a memória relacionadas aos aspectos ferroviários, como, por exemplo: aspectos da construção, desenvolvimento e/ou declínio da estrada de ferro, etc. (BORGES; FRAGA, 2015).

A respeito desse último aspecto, é perceptível que a história e a memória formam lado a lado um caminho importante para um tipo de turismo que favoreça "o sentido de coletivo de vida em sociedade [...] [levando] a valorização da cultura local e o sentimento de pertencimento" proposto por Irving (2009) na reinvenção das reflexões sobre turismo de base comunitária. A seguir isso será mais detalhado.

\section{BUSCA POR CONEXÕES A PARTIR DA HISTÓRIA E DA MEMÓRIA ÚTEIS AO PLANEJAMENTO E A GESTÃO}

As discussões acerca de memória e história já receberam importantes contribuições de especialistas sobre o tema. Nora (1993) afirma que a memória histórica filtra, acumula, capitaliza e transmite, ou seja, a memória coletiva tanto conserva por um momento a recordação de uma experiência intransmissível quanto também apaga e recompõe ao seu gosto, em função das necessidades de momento e das leis do imaginário ${ }^{1}$.

É relevante considerar que memória e história não são sinônimas, pois a memória deve ser sempre suspeita para a história. A memória é um fenômeno sempre atual, um elo vivido no eterno presente, a história é uma representação do passado. O estudo dos lugares de memória cruza dois movimentos que se combinam e se remetem aos instrumentos de base do trabalho histórico, aos objetos mais simbólicos de nossa memória. Um é o movimento puramente historiográfico, o momento de um retorno reflexivo, da

\footnotetext{
1 Conceito polissêmico que ganha constantes ressignificações e, dessa forma, apresentamos uma possível definição a partir das reflexões de Pesavento (1995, p. 24): “o imaginário é, pois, representação, evocação, simulação, sentido e significado, jogo de espelhos onde o 'verdadeiro' e o aparente se mesclam, estranha composição onde a metade visível evoca qualquer coisa de ausente e difícil de perceber. Persegui-lo como objeto de estudo é desvendar um segredo, é buscar um significado oculto, encontrar a chave para desfazer a representação do ser e parecer".
} 
história sobre ela mesma. O outro é um movimento propriamente histórico, ou seja, o fim de uma tradição de memória.

A passagem da memória à história fez com que cada grupo fosse obrigado a redefinir a revitalização de sua própria história. O fim da história-memória multiplicou as memórias particulares que reclamam sua própria história. Quanto menos a memória é vivida coletivamente, mais ela tem necessidade de homens particulares e fazem deles próprios homens-memória. Nora (1993) conclui que a memória dita o que a história escreve, afinal, a memória pendura-se em lugares como a história em acontecimentos, e esses acontecimentos não podem ser separados da identidade local.

Assim, considerando as bases geográficas dos trechos ferroviários (origem/destino), visitantes (incluindo os turistas) e visitados (os anfitriões) poderão formar laços de pertencimento em função de uma série de elementos, sendo aspectos relevantes tanto da história quanto da memória. Na próxima seção são desenhados critérios e selecionados os casos para o estudo.

\section{CONSTRUINDO CRITÉRIOS E SELECIONANDO CASOS QUE PODEM SER ALVOS DE PLANEJAMENTO E/OU GESTÃO ENVOLVENDO TFBC}

Este estudo é exploratório e deriva das aproximações das autoras no tratamento das disciplinas de “Transportes e Turismo", "Turismo Cultural Ferroviário" e "Planejamento do Turismo Histórico Cultural" em Curso de Bacharelado em Turismo. A definição de critérios (ver Figura 1) foi baseada no levantamento bibliográfico para a composição de referencial teórico sobre a temática, evidenciada na seção anterior.

Na Figura 1 é nítido que de um lado tem-se o "Turismo Ferroviário" (TF) que pode ocorrer independente da "Base Comunitária", e, de outro, a "Base Comunitária" (BC), que também pode existir e não ser incluída no desenvolvimento do "Turismo Ferroviário", sendo os critérios definidos por Fabrino et al. (2012) essenciais ao aprofundamento desta discussão. Contudo, neste estudo preliminar, os pontos de ligação construídos neste esquema, que se assemelha à letra "T", (ver Figura 1) são:

(1) referências geográficas (origem/destino); e,

(2) as referências históricas e suas vinculações com a memória.

\begin{tabular}{|c|c|c|c|c|}
\hline \multicolumn{2}{|c|}{ Turismo Ferroviário (TF) } & \multirow[b]{2}{*}{$\begin{array}{l}\text { (1) Referências } \\
\text { geográficas }\end{array}$} & \multirow{2}{*}{$\begin{array}{l}\text { (2) Referências } \\
\text { históricas e aspectos } \\
\text { relacionados à } \\
\text { memória }\end{array}$} & \multirow{2}{*}{$\begin{array}{c}\text { Base comunitária } \\
\text { Comunidade Receptora }\end{array}$} \\
\hline $\mathrm{N}$ & $\begin{array}{l}\text { Trem Turístico } \\
\text { e Cultural }\end{array}$ & & & \\
\hline Número & $\begin{array}{l}\text { Identificação } \\
\text { do Trem } \\
\text { Turístico e } \\
\text { Cultural }\end{array}$ & $\begin{array}{l}\text { Origem/destino da } \\
\text { viagem ferroviária }\end{array}$ & $\begin{array}{c}\text { Acontecimentos } \\
\text { históricas e/ou } \\
\text { memórias referentes } \\
\text { à ferrovia }\end{array}$ & $\begin{array}{l}\text { Identificação de } \\
\text { possíveis relações entre } \\
\text { a comunidade receptora } \\
\text { e a operação ferroviária } \\
\text { turística }\end{array}$ \\
\hline
\end{tabular}

Figura 1 - Critérios Turismo Ferroviário (TF) e Base Comunitária (BC)

Fonte: Elaboração própria 
Visando abranger a diversidade da oferta ferroviária turística nacional, consideraram-se os seguintes critérios para a seleção dos dez casos: (1) localização geográfica variada; (2) tecnologias ferroviárias diversas (ex.: locomotivas a vapor, trens eletrificados, etc.).

Com base na oferta ferroviária turística brasileira identificada através do website do Ministério do Turismo (BRASIL, s.d.) e da Associação Brasileira das Operadoras de Trens Turísticos e Culturais (ABOTTC), foram selecionados dez casos para apresentação e discussão. A distribuição dos casos por unidades da Federação (UF) é a seguinte: (1) Espírito Santo, (1) Rio de Janeiro, (3) São Paulo, (2) Minas Gerais na Região Sudeste do País; (2) Santa Catarina e (1) Rio Grande do Sul. A seguir são apresentados e discutidos os dez casos.

\section{BUSCANDO CONEXÕES}

O objetivo desta seção é apresentar e discutir os dez casos selecionados. De acordo com a Figura 1, a Tabela 2 apresenta de um lado dados sobre a oferta de trens turísticos e culturais que compõem o Turismo Ferroviário (TF) nacional, e, de outro, elementos da história e vinculações com a memória como balizadores para a discussão de possíveis elos e pertencimentos relacionados à "Base Comunitária". A última coluna trata especificamente de possíveis relações entre a comunidade receptora (atores e organizações) e a operação ferroviária turística, que foi identificada a partir da busca em websites.

Tabela 2 - Turismo Ferroviário (TF) e Base Comunitária (BC)

\begin{tabular}{|c|c|c|c|c|c|}
\hline \multicolumn{4}{|c|}{ Turismo Ferroviário (TF) } & \multicolumn{2}{|c|}{ Base Comunitária (BC) } \\
\hline $\mathrm{N}$ & UF & $\begin{array}{l}\text { Identificação } \\
\text { do Trem } \\
\text { Turístico e } \\
\text { Cultural }\end{array}$ & $\begin{array}{c}\text { Origem/ } \\
\text { destino } \\
\text { da viagem } \\
\text { ferroviária }\end{array}$ & $\begin{array}{c}\text { Acontecimentos históricos } \\
\text { e/ou memórias referentes } \\
\text { à ferrovia }\end{array}$ & $\begin{array}{c}\text { Identificação de } \\
\text { possíveis relações entre } \\
\text { a comunidade receptora } \\
\text { e a operação ferroviária } \\
\text { turística }\end{array}$ \\
\hline 1 & $\mathrm{SP}$ & $\begin{array}{l}\text { Viação Férrea } \\
\text { Campinas - } \\
\text { Jaguariúna }\end{array}$ & $\begin{array}{l}\text { Campinas/ } \\
\text { Tanquinho/ } \\
\text { Jaguariúna }\end{array}$ & $\begin{array}{l}\text { História das fazendas. } \\
\text { História da ferrovia. }\end{array}$ & $\begin{array}{l}\text { Parceria com empresa } \\
\text { de alimentos e bebidas, } \\
\text { atuação de grupo de } \\
\text { músicos com canções } \\
\text { brasileiras. }\end{array}$ \\
\hline 2 & SP & $\begin{array}{l}\text { Trem do } \\
\text { Imigrante* }\end{array}$ & São Paulo & $\begin{array}{l}\text { História do café e da } \\
\text { imigração. }\end{array}$ & Museu \\
\hline 3 & MG & Trem das Águas & $\begin{array}{l}\text { São Lourenço/ } \\
\text { Soledade de } \\
\text { Minas }\end{array}$ & História do Império. & $\begin{array}{l}\text { Feira de artesanato, } \\
\text { cantores locais a bordo, } \\
\text { museu ferroviário, produtos } \\
\text { (alimentos e bebidas) } \\
\text { locais, música sertaneja e } \\
\text { culinária mineira (local). }\end{array}$ \\
\hline 4 & MG & $\begin{array}{l}\text { Trem da Serra } \\
\text { da Mantiqueira }\end{array}$ & $\begin{array}{l}\text { Passa Quatro/ } \\
\text { Coronel } \\
\text { Fulgêncio }\end{array}$ & $\begin{array}{c}\text { História do Império, } \\
\text { História da Revolução } \\
\text { Constitucionalista de } 1932 .\end{array}$ & $\begin{array}{l}\text { Exposição fotográfica, feira } \\
\text { de artesanato, produtos } \\
\text { (alimentos e bebidas) } \\
\text { locais, cantores locais a } \\
\text { bordo, música sertaneja e } \\
\text { culinária mineira (local). }\end{array}$ \\
\hline
\end{tabular}




\begin{tabular}{|c|c|c|c|c|c|}
\hline 5 & $\mathrm{SC}$ & $\begin{array}{c}\text { Trem da Serra } \\
\text { do Mar }\end{array}$ & $\begin{array}{l}\text { Rio Negrinho / } \\
\text { Rio Natal (em } \\
\text { São Bento do } \\
\text { Sul) }\end{array}$ & $\begin{array}{c}\text { "históricos carros de } \\
\text { passageiros" [...] “encontro } \\
\text { entre a natureza e o } \\
\text { saudosismo" (ABOTTC, } \\
\text { 2010). }\end{array}$ & $\begin{array}{c}\text { Museu dinâmico da Maria } \\
\text { Fumaça, grupo folclórico, } \\
\text { pratos típicos poloneses, } \\
\text { existência de colônia } \\
\text { polonesa. }\end{array}$ \\
\hline 6 & ES & $\begin{array}{l}\text { Trem das } \\
\text { Montanhas } \\
\text { Capixabas }\end{array}$ & $\begin{array}{l}\text { Viana/ } \\
\text { Domingos } \\
\text { Ferreira/ } \\
\text { Marechal } \\
\text { Floriano } \\
\text { (Araguaia) }\end{array}$ & $\begin{array}{l}\text { Influência Açoriana. } \\
\text { Homenagem a Maria } \\
\text { Leopoldina, primeira } \\
\text { imperatriz do Brasil. }\end{array}$ & $\begin{array}{c}\text { Artesanato, doces e } \\
\text { bolachas. }\end{array}$ \\
\hline 7 & SP & $\begin{array}{l}\text { Trem dos } \\
\text { Ingleses* }\end{array}$ & $\begin{array}{l}\text { Paranapiacaba } \\
\text { (distrito de } \\
\text { Santo André) }\end{array}$ & $\begin{array}{c}\text { História da primeira } \\
\text { ferrovia do estado de São } \\
\text { Paulo. }\end{array}$ & $\begin{array}{c}\text { Atração do Museu Funicular } \\
\text { de Paranapiacaba, } \\
\text { monitores contam parcela } \\
\text { da história da ferrovia. }\end{array}$ \\
\hline 8 & $\mathrm{SC}$ & $\begin{array}{l}\text { Estrada de } \\
\text { Ferro Santa } \\
\text { Catarina }\end{array}$ & Apiúna & $\begin{array}{c}\text { A história da estrada de } \\
\text { ferro se relaciona com a } \\
\text { Colônia Blumenau fundada } \\
\text { em } 1850 . \text { Única ferrovia a } \\
\text { usar capital e tecnologia } \\
\text { alemã. }\end{array}$ & $\begin{array}{l}\text { Palestra sobre a história } \\
\text { da ferrovia no pátio da } \\
\text { Usina (final), alimentos } \\
\text { e bebidas, artesanato } \\
\text { variado no embarque, dois } \\
\text { restaurantes locais com } \\
\text { comida colonial e pratos } \\
\text { à base de peixe, artistas } \\
\text { locais em restaurante } \\
\text { próximo ao embarque. }\end{array}$ \\
\hline 9 & RS & Trem do Vinho & $\begin{array}{l}\text { Bento } \\
\text { Gonçalves/ } \\
\text { Carlos } \\
\text { Barbosa/ } \\
\text { Garibaldi }\end{array}$ & $\begin{array}{c}\text { Sem informação específica, } \\
\text { embora existam } \\
\text { vinculações com a história } \\
\text { e a memória evidentes. }\end{array}$ & $\begin{array}{c}\text { Coral típico italiano, teatro, } \\
\text { show gaúcho, degustação } \\
\text { de vinho e espumante. }\end{array}$ \\
\hline 10 & RJ & $\begin{array}{l}\text { Estrada de } \\
\text { Ferro do } \\
\text { Corcovado }\end{array}$ & Rio de Janeiro & $\begin{array}{l}\text { Passeio [ferroviário] } \\
\text { turístico mais antigo do } \\
\text { País. Inaugurado em } 1884 \\
\text { pelo Imperador. Primeira } \\
\text { ferrovia eletrificada do } \\
\text { País. “ (...) o passageiro } \\
\text { faz um passeio através } \\
\text { da história do Brasil” } \\
\text { (ABOTTC, 2010). }\end{array}$ & $\begin{array}{l}\text { Ajuda a manter a Floresta } \\
\text { da Tijuca. Apresentação de } \\
\text { grupo de samba no trajeto. }\end{array}$ \\
\hline
\end{tabular}

*Não é considerado um trem turístico e sim um trem de caráter histórico cultural (ABOTTC, 2010).

Fonte: Elaborado pelas autoras com base em BRASIL (s.d.), ABOTTC (2010).

Embora tenha se objetivado extrair ao máximo as informações sobre os critérios determinados na Figura 1 nas consultas aos websites analisados, destacou-se na Tabela 2 aqueles julgados como mais relevantes para a discussão proposta neste trabalho. De imediato, nota-se a partir da Tabela 2 que os trens turísticos e culturais estudados (10 casos) são bastante heterogêneos (diferentes entre si) e podem dialogar com vários segmentos do mercado turístico em função das características que apresentam relacionadas à história e memória, tal como o turismo nostálgico, entre outras. A seguir o texto é subdividido em duas partes, a primeira trata da localização geográfica, de aspectos relativos à história e à memória e a segunda sobre as possíveis relações que podem ser destacadas entre a comunidade receptora e a operação ferroviária turística a partir da Tabela 2. 


\section{LOCALIZAÇÃO GEOGRÁFICA, HISTÓRIA E MEMÓRIA}

Após a sistematização de dez exemplos brasileiros (ver Tabela 2) que aproximam o turismo ferroviário da discussão da base comunitária, é importante apresentar as nossas primeiras conclusões sobre o assunto:

Tabela 3 - Localização Geográfica, História e Memória

\begin{tabular}{|l|l|}
\hline $\begin{array}{l}\text { Localização } \\
\text { Geográfica }\end{array}$ & $\begin{array}{l}\text { Todos os casos apresentados estão localizados nas regiões Sul e Sudeste do } \\
\text { Brasil. }\end{array}$ \\
\hline $\begin{array}{l}\text { História e } \\
\text { Memória }\end{array}$ & $\begin{array}{l}\text { Os séculos XIX e XX são as principais referências históricas. O período do Segundo } \\
\text { Getúlio Vargas (1930-1934) são as delimitações temporais que fazem parte desse } \\
\text { imaginário que permite trazer, à cena turística, os passeios e itinerários temáticos } \\
\text { ferroviários associados à história e à memória do Brasil. }\end{array}$ \\
\hline
\end{tabular}

Fonte: Elaboração própria

Com base na Tabela 3, nota-se que, em linhas gerais, o Segundo Reinado foi marcado tanto pela expansão cafeeira quanto pela formação do Estado liberal monárquico. Ao mesmo tempo em que a escravidão era a realidade daquela época, a imigração avançava em terras brasileiras. Na atualidade, o café, a imigração e a ferrovia são elementos resgatados nos temas históricos e/ou ligados à memória que potencializam os percursos apresentados. Em linhas gerais, a consolidação do café como principal produto na economia agroexportadora representou um saldo muito positivo para o desenvolvimento comercial internacional no Brasil. Assim, a ascensão da economia cafeeira repercutiu no imaginário de uma região e perdurou-se por intermédio de gerações que parecem buscar, na atualidade, a fonte de inspiração baseada no esplendor do século XIX.

Naquele período, a Europa vivia momentos agitados com destaque para os processos de unificações italiana e alemã, e as ações imperialistas que se espalhavam pelo mundo. Desse modo, muitos imigrantes chegaram ao Brasil com a perspectiva de ascensão social e, portanto, apresentando diferenças culturais em relação aos brasileiros. A imigração trouxe consigo vários elementos como, por exemplo, a língua, os costumes, a música, a dança, os festejos e a culinária, que se disseminaram e ganharam ressignificações pela cultura brasileira.

Cada um a sua maneira, esses traços são retomados em alguns dos trechos ferroviários que integram os dez exemplos brasileiros selecionados. Assim, as locomotivas a vapor proporcionam aos turistas uma ambientação histórica e/ou memorialista marcada pela suntuosidade de um tempo. Vale destacar que, em muitos casos, a emigração para o Brasil ocorreu para fugir dos tempos difíceis europeus, mas, certamente, não são as agruras daqueles tempos que se pretende resgatar no turismo ferroviário na época presente (BATALHA, 2003).

No Brasil, a Primeira República herdou e processou muitos elementos formativos do País no reinado de D. Pedro II. Desde as últimas décadas do século XIX, muitas cidades latino-americanas começaram a experimentar alterações não só na estrutura social, mas também na sua fisionomia. Com a multiplicação e, consequentemente, o aumento de sua diversidade, além da paisagem urbana, os costumes também se alteraram, bem como as formas de pensar que influenciavam a mudança do uso e da constituição do espaço físico. A palavra de ordem parecia ser o progresso, e diante dos olhos atentos da população e dos viajantes europeus, a metamorfose urbana concretizou-se no espaço de 20 anos finalizando com a efervescência da década de 1920. 
Além disso, a industrialização parecia ser uma das principais marcas daqueles tempos eufóricos e otimistas. Entretanto, a eclosão da Primeira Guerra Mundial (1914-1918) e a crise de 1929 e seus desdobramentos colocaram em xeque o Estado liberal. No Brasil, em 1932, as elites paulistas, que eram as mais favorecidas pelo sistema que vigorou na Primeira República, almejavam, com esse movimento, reaver o domínio político que haviam perdido com a Revolução de 1930. Somados a isso, os revoltosos reivindicavam uma nova Constituição e clamavam pela realização de eleições presidenciais. O governo provisório de Vargas parecia estar com os dias contados. No imaginário popular, de forma metafórica, a "locomotiva São Paulo" parecia puxar os demais estados da Federação e dava insistentemente o seu sinal de partida.

\section{PERCEPÇÕES SOBRE LAÇOS COM AS COMUNIDADES RECEPTORAS}

Após essa contextualização histórica, é fundamental discutir a relação entre a comunidade receptora e a operação ferroviária turística na atualidade. Certamente, o planejamento e as políticas públicas são fundamentais para que exista sintonia e integração entre as partes envolvidas neste processo (LOHMANN; FRAGA; CASTRO, 2013; FRAGA et al., 2015).

No presente, quando os residentes reconhecem e valorizam o seu patrimônio cultural ${ }^{2}$, eles têm condições de apresentar de forma mais apropriada aquilo que lhes pertencem e há uma relação direta com a possibilidade de experiências exitosas nos trens turísticos e culturais. Por fim, a interpretação local do turismo pelo olhar da comunidade que ali reside é capaz de produzir alternativas importantes para essa modalidade de turismo.

Como observado na Tabela 2, de maneira geral, a culinária local é um dos pontos fortes a ser apreciado pelos turistas que embarcam nos trens turísticos e culturais. Na história da humanidade, os alimentos e bebidas adquirem características diferenciadas que se transformam em elemento cultural podendo revelar de forma significativa a população visitada ao proporcionar uma viagem pelos sabores (POSSAMAI; PECCINI, 2011). Assim, parece que há um espaço em algumas operações ferroviárias turísticas para ofertar aos turistas os pratos típicos que podem mostrar elementos históricos que são memoráveis daquela realidade geográfica específica. As celebrações expressas nas músicas e danças são outras potencialidades turísticas que merecem integrar o planejamento do turismo ferroviário que busca conexões com o turismo de base comunitária no Brasil da atualidade.

\section{CONSIDERAÇÕES FINAIS}

Neste estudo ficou evidente que existem conexões entre turismo ferroviário e turismo de base comunitária, o que possibilita esboçar nestas considerações finais aspectos conceituais para o TFBC. Assim, entendese que o TFBC é aquele no qual a relação entre a ferrovia e o turismo deve ser organizada e estruturada considerando os laços sociais entre visitantes (no caso os turistas) e os visitados (comunidade receptora), levando a experiências permeadas pelo sentimento de pertencimento, evocadas pela valorização da cultura local através de elementos relacionados à história e à memória.

2 A palavra "patrimônio" pode assumir sentidos diversos. No caso do patrimônio cultural imaterial ou intangível, pode ser denominado como as práticas, as representações e técnicas que pertencem à comunidade. (FUNARI; PINSKY, 2012). 
Embora o estudo não tenha focado a análise da relação entre visitantes (turistas) e visitados (comunidade receptora), e só tenha enfocado o que é expresso pela oferta ferroviária turística por websites específicos, ficou evidente que há um grande potencial para a discussão de "conexões" entre turismo ferroviário e turismo de base comunitária. Novos estudos poderão ampliar o número de casos alcançando toda a realidade nacional e estabelecer outros parâmetros para o alargamento da discussão teórico-conceitual sobre Turismo Ferroviário de Base Comunitária (TFBC), notadamente incluindo nas discussões e análises os tópicos destacados por Fabrino et al. (2012) que merecem atenção.

Para tanto, seria relevante considerar a realização de trabalho de campo envolvendo construção de questionários e entrevistas com atores e organizações das localidades. Além disso, poderá se considerar o estudo detalhado de dados disponíveis em websites de cada operadora ferroviária turística.

\section{REFERÊNCIAS}

ABOTTC. Disponivel em: 〈http://www.abottc.com.br〉. Acesso em: 7 set. 2015.

ABOTTC, SEBRAE. 0 Perfil dos Clientes dos Trens Turísticos e Culturais: percepções e comportamentos dos turistas. Relatório da Pesquisa de Grupos Focais. Abril, 2015.

ALLIS, T. Ferrovia e turismo cultural - alternativa para o futuro da Vila de Paranapiacaba (SP). Turismo em Análise, São Paulo, v. 13, n. 2, p. 29-53, 2002.

BATALHA, C. H. M. Formação da classe operária e projetos de identidade coletiva. In: FERREIRA, J.; DELGADO, L. 0 Brasil Republicano: o tempo do liberalismo excludente: da proclamação da República à Revolução de 1930. Rio de Janeiro: Civilização Brasileira, p. 161-190, 2003.

BAUMAN, Z. Globalização: as consequências humanas. Rio de Janeiro: Zahar. 1999.

BRASIL. Ministério do Turismo. Cartilha de orientação para a proposição de projetos de trens turísticos e culturais. 2010. Disponível em 〈http://www.turismo.gov.br/sites/default/turismo/o_ministerio/ publicacoes/downloads_publicacoes/cartilha-final-b.pdf>. Acesso em: 7 set. 2015.

BRASIL. Ministério do Turismo. Trens Turísticos em Operação. (s.d.) Disponível em: 〈http://www. turismo.gov.br/export/sites/default/turismo/noticias/todas_noticias/Noticias_download/lista_ trens_turisticos_em_operacao.doc>.Acesso em: 7 abr. 2015.

BURSZTYN, I.; BARTHOLO, R.; DELAMARO, M. Turismo para quem? Sobre caminhos de desenvolvimento e alternativas para o turismo no Brasil. In: . Turismo de Base Comunitária: diversidades de olhares e experiências brasileiras. Rio de Janeiro: Letra e Imagem. p. 76-91, 2009.

FABRINO, N. H.; COSTA, H. A.; NASCIMENTO, E. P. do. Turismo de Base Comunitária (TBC): elementoschaves para aferir seu desempenho na perspectiva da sustentabilidade. Revista Brasileira de Ecoturismo, São Paulo, v. 5, n. 3, p. 546-559, 2012.

FRAGA, C. Transporte Terrestre e Destinos Turísticos. In: Transportes e Destinos Turísticos: planejamento e gestão. Rio de Janeiro: Elsevier/Campus. p. 177-212, 2013.

FRAGA, C. C. L. Contribuição metodológica para a implantação de trens turísticos no Brasil. Tese (Doutorado). Programa de Engenharia de Transportes/Coppe. Universidade Federal do Rio de Janeiro. 2011. 
FRAGA, C. C. L.; SANTOS, M. P. S. S.; RIBEIRO, S. C. Railroad tourism in Brazil. In: CONLIN, M. V.; BIRD, R. Railway Heritage and Tourism: global perspective. Channel View Publications. p. 137-150, 2014.

FRAGA, C. et al. Três Picos e Entroncamento: uma discussão luso-brasileira sobre a importância do turismo ferroviário. In: FARIA, I. C. S.; BORGES, V. L. B. Vozes do Turismo: incursões interdisciplinares e relatos de experiências. Rio de Janeiro: Multifoco. p. 221-246, 2015.

FRAGA, C.; FROSSARD, M. A construção de sentidos e significados, pela publicidade, a respeito da relação entre ferrovia e turismo, o caso do Reino Unido. 2015. XI SEMINÁRIO DA ASSOCIAÇÃO NACIONAL DE PÓS-GRADUAÇÃO E PESQUISA EM TURISMO - ANPTUR. Anais... Disponível em: 〈http:// www.anptur.org.br/novo_portal/anais_anptur/anais_2014/arquivos/DCL/trabalhos-dcl-dcl2.html>. Acesso em: 10 out. 2015.

FUNARI, P. P.; PINSKY, J. (Org.). Turismo e Patrimônio Cultural. São Paulo: Contexto, 2012.

IRVING, M. A. Reinventando a reflexão sobre turismo de base comunitária. In: BARTHOLO, R.; SANSOLO, D. G.; BURSZTYN, I. (Org.). Turismo de Base Comunitária: diversidades de olhares e experiências brasileiras. Rio de Janeiro: Letra e Imagem. p. 108-121, 2009.

LOHMANN, G.; FRAGA, C.; CASTRO, R. Transportes e Destinos Turísticos: planejamento e gestão. Rio de Janeiro: Elsevier, 2013.

NORA, P. Entre memória e história: a problemática dos lugares. Revista de História da PUC/SP. São Paulo, n. 10, p. 7-28, 1993.

PALHARES, G. L. Transportes Turísticos. São Paulo: Aleph. 2002.

PESAVENTO, S. Em busca de uma outra história: imaginando o imaginário. Revista Brasileira de História, São Paulo, v. 15, n. 29, p. 1-15, 1995.

POSSAMAI, A. M. D. P.; PECCINI, R. (Org.). Turismo, história e gastronomia: uma viagem pelos sabores. Caxias do Sul: Educs. 2011. 